\title{
Pengaruh pemakaian peranti ortodonti cekat terhadap status psikososial
}

\author{
Zulfan Muttaqin ${ }^{1 \star}$, Lina $\mathrm{Hadi}^{1}, \mathrm{Naomi}^{1}$ \\ ${ }^{1}$ Fakultas Kedokteran Gigi Universitas Prima Indonesia
}

\begin{abstract}
ABSTRAK
Penderita maloklusi sering mendapat respon buruk yang berdampak terhadap status psikososial individu. Hal ini mengakibatkan meningkatnya minat pemakaian peranti ortodonti cekat dari waktu ke waktu dikarenakan keinginan untuk memperbaiki estetika gigi. Penelitian ini bertujuan untuk mengetahui pengaruh pemakaian peranti ortodonti cekat terhadap status psikososial mahasiwa Fakultas Kedokteran Gigi Universitas Prima Indonesia. Jenis penelitian ini adalah survei analitik dengan desain cross sectional. Jumlah sampel dalam penelitian ini sebanyak 34 mahasiswa, terdiri dari 17 orang yang belum pernah memakai peranti ortodonti cekat dan 17 orang yang telah selesai pemakaian peranti ortodonti cekat. Teknik pengambilan sampel dengan purposive sampling. Status psikososial dikelompokkan menjadi status psikososial baik, sedang, dan buruk. Berdasarkan hasil penelitian didapatkan sebelum pemakaian peranti ortodonti cekat didominasi oleh status psikososial sedang sebanyak 13 orang $(76,4 \%)$. Sedangkan setelah pemakaian peranti ortodonti cekat didominasi oleh status psikososial baik sebanyak 14 orang (82,4\%). Uji Chi-Square ( $p$ value 0,000). Kesimpulan penelitian ini adalah terdapat pengaruh antara pemakaian peranti ortodonti cekat dengan status psikososial mahasiswa Fakultas Kedokteran Gigi Universitas Prima Indonesia.
\end{abstract}

Kata kunci: peranti ortodonti cekat, psikososial

\begin{abstract}
People with malocclusion of ten get a bad response that impact their psychosocial status. This resulted in increased interest in the usage of fixed orthodontic appliances from time to time due to the desire to improve dental aesthetics. This research aims to see the effect of fixed orthodontic appliances on the psychosocial status of Prima Dentistry Students. This research is analytic survey with cross sectional design. Samples of this research are 34 students, consist of 17 students that never used fixed orthodontic appliances and 17 students that have finished their fixed orthodontic usage. The sampling technique was done with purposive sampling. Psychosocial status was grouped into well, moderate, and poor. Psychosocial status of students before the usage of fixed orthodontic appliances was dominated with moderate psychosocial status consist of 13 students (76,4\%). While the psychosocial status of students after the usage of fixed orthodontic appliances was dominated with well psychosocial status consist of 14 students (82,4\%). Chi-square test ( $p$ value 0,000). The conclusion of this study is that there is an effect between the usage of fixed orthodontic appliances and the psychosocial status of Prima Dentistry Students.
\end{abstract}

Keywords: fixed orthodontic appliances, psychosocial

`Alamat korespondensi: mottakeane@gmail.com DOI: $10.34012 / j p m s . v 3 i 2.2160$

\section{PENDAHULUAN}

Gigi dan mulut adalah suatu kesatuan yang terintegrasi terhadap tubuh secara menyeluruh. Gangguan kesehatan gigi dan mulut akan berpengaruh terhadap kesehatan tubuh baik secara langsung maupun tidak langsung. ${ }^{1}$ Pada tahun 2018, Riset Kesehatan Dasar (Rikesdas) Nasional mencatat gangguan kesehatan gigi dan mulut di Indonesia sebesar 57,6\%. Angka tersebut menunjukkan bahwa masyarakat Indonesia memiliki gangguan kesehatan gigi dan mulut yang tergolong tinggi. Salah satu anomali gigi dan mulut yang banyak ditemukan adalah maloklusi. Di Indonesia, maloklusi menempati posisi ketiga dengan prevalensi sebesar $80 \%$. Angka tersebut tergolong tinggi mengingat kurangnya 
kesadaran masyarakat untuk merawat gigi. ${ }^{2}$ Oklusi pasien dapat diperiksa dengan meninjau hubungan kontak rahang atas dan rahang bawah saat pasien menggigit secara normal. ${ }^{3}$

Menurut World Health Organization (WHO), maloklusi adalah kelainan yang mengakibatkan kerusakan atau mengurangi fungsi peran gigi sehingga mengindikasikan perawatan apabila mengganggu kesehatan fisik dan emosional pasien. ${ }^{4}$ Ditinjau dari aspek kebersihan, gigi berjejal akan sulit dibersihkan karena posisi gigi berjejal mengakibatkan makanan menempel di permukaan gigi, sehingga mendorong terjadinya karies gigi, gingivitis, bahkan penyakit periodontitis yang mengakibatkan gigi tidak dapat bertahan sehingga harus diekstraksi. ${ }^{5}$

Ortodonti merupakan cabang kedokteran gigi yang berfungsi dalam mengoreksi struktur susunan gigi dan relasi rahang agar tercapai fungsi peran gigi yang optimal. Perawatan ortodonti bertujuan untuk menciptakan oklusi gigi yang sempurna secara fungsi maupun posisinya, agar terbentuk keserasian antar oklusi gigi, relasi rahang dan estetika wajah secara keseluruhan. ${ }^{6}$ Berdasarkan penelitian American Association of Orthodontists, dalam kurun waktu 2 tahun yakni tahun 2010-2012 minat untuk melakukan perawatan ortodonti pada pasien dewasa meningkat sebesar $14 \%$. Hal serupa juga terjadi pada pasien berusia di bawah 17 tahun, yakni minat untuk melakukan perawatan ortodonti meningkat sebesar $22 \% .^{7}$

Salah satu alasan masyarakat melakukan perawatan ortodonti adalah untuk memenuhi kebutuhan estetika yang bertujuan memperbaiki penampilan dan psikososial individu. Penderita maloklusi sering mendapat respon buruk dari orang lain, seperti hinaan atau julukan yang berdampak pada hubungan sosial individu. Hal tersebut akan mempengaruhi perkembangan individu dimana pada fase remaja, seseorang mengalami perubahan fisik dan psikososial sehingga penampilan wajah dan estetika gigi merupakan faktor penting dalam menjaga penampilan diri. ${ }^{8}$ Chaplin (2011) mengemukakan psikososial membahas hubungan sosial terhadap aspek psikologis. ${ }^{9}$ Salah satu bagian dari psikologis manusia adalah penghargaan terhadap diri sendiri. Hubungan sosial akan dipengaruhi oleh cara individu menilai dan menghargai dirinya. ${ }^{10}$ Individu lebih sering dihina karena estetika gigi yang buruk dibandingkan hal lain seperti pakaian, berat telinga, dan sebagainya. ${ }^{11}$ Penelitian ini bertujuan untuk mengetahui pengaruh pemakaian peranti ortodonti cekat terhadap status psikososial mahasiswa Fakultas Kedokteran Gigi Universitas Prima Indonesia.

\section{METODE}

Penelitian ini merupakan penelitian survei analitik dengan desain cross-sectional. Penelitian ini dilakukan selama bulan Oktober tahun 2021 di Fakultas Kedokteran Gigi Universitas Prima Indonesia. Populasi pada penelitian ini adalah seluruh mahasiswa Fakultas Kedokteran Gigi Universitas Prima Indonesia. Penentuan subjek penelitian dilakukan dengan teknik purposive sampling yaitu suatu teknik pengambilan sampel sesuai dengan kriteria inklusi. Sampel terdiri dari 17 orang yang belum pernah memakai peranti ortodonti cekat dan 17 orang yang telah selesai memakai peranti ortodonti cekat. Penelitian diawali setelah peneliti mendapatkan izin dari pihak Fakultas Kedokteran Gigi Universitas Prima Indonesia. Kuesioner yang digunakan dalam penelitian ini adalah Psychosocial Impact of Dental Aesthetics Questionnaire (PIDAQ) yang terdiri dari 23 pertanyaan. Jawaban responden diukur berdasarkan ketentuan skala Likert: $0=$ tidak setuju; $1=$ =sedikit setuju; $2=$ agak setuju; $3=$ setuju; dan $4=$ sangat setuju. Total keseluruhan pertanyaan dijumlah dan dikelompokkan menjadi status psikososial berdasarkan ketentuan: 0-31=psikososial baik; 32-62=psikososial sedang; 63-92= psikososial buruk. Lalu data diolah menggunakan uji Chi-Square.

\section{HASIL}

Tabel 1 menunjukkan bahwa mahasiswa Fakultas Kedokteran Gigi Universitas Prima Indonesia yang memenuhi kriteria inklusi penelitian lebih didominasi oleh perempuan berjumlah 24 orang 
(70,6\%) dan laki-laki berjumlah 10 orang (29,4\%). Ditinjau dari usia, usia 18-21 tahun berjumlah 20 orang $(58,9 \%)$ dan usia $22-25$ tahun berjumlah 14 orang $(41,1 \%)$.

Tabel 1. Karakteristik responden $(\mathrm{n}=34)$

$\begin{array}{lcc}\text { Variabel } & \text { Jumlah } & \text { Persentase } \\ \text { Jenis kelamin } & & \\ \quad \text { Perempuan } & 24 & 70,6 \\ \quad \text { Laki-laki } & 10 & 29,4 \\ \text { Usia } & & \\ \text { 18-21 tahun } & 20 & 58.9 \\ \text { 22-25 tahun } & 14 & 41.1\end{array}$

Tabel 2 menunjukkan bahwa mahasiswa Fakultas Kedokteran Gigi Universitas Prima Indonesia yang belum pernah melakukan pemakaian peranti ortodonti cekat memiliki status psikososial baik berjumlah 2 orang $(11,8 \%)$, status psikososial sedang berjumlah 13 orang $(76,4 \%)$, dan status psikososial buruk berjumlah 2 orang $(11,8 \%)$.

Sedangkan mahasiswa Fakultas Kedokteran Gigi Universitas Prima Indonesia yang telah selesai melakukan pemakaian peranti ortodonti cekat memiliki status psikososial baik berjumlah 14 orang $(82,4 \%)$, dan status psikososial sedang berjumlah 3 orang $(17,6 \%)$. Hasil uji chi-square $0,000<0,005$ menjelaskan bahwa terdapat pengaruh pemakaian peranti ortodonti cekat terhadap status psikososial mahasiswa Fakultas Kedokteran Gigi Universitas Prima Indonesia.

Tabel 2. Status psikososial mahasiswa sebelum dan setelah pemakaian peranti ortodonti cekat

\begin{tabular}{cccccc}
\hline $\begin{array}{c}\text { Pemakaian peranti } \\
\text { ortodonti cekat }\end{array}$ & Baik & Sedang & Buruk & Total (n\%) & p value \\
\hline Sebelum & $2(11,8 \%)$ & $13(76,4 \%)$ & $2(11,8 \%)$ & $17(100 \%)$ & 0,000 \\
Sesudah & $14(82,4 \%)$ & $3(17,6 \%)$ & $0(0 \%)$ & $17(100 \%)$ & \\
\hline
\end{tabular}

\section{PEMBAHASAN}

Saat ini, senyum dipertimbangkan sebagai bagian penting dari wajah yang mempengaruhi daya tarik seseorang sehingga estetika gigi sangat penting dalam menjaga harga diri seseorang. Terlebih lagi, standar penampilan yang diciptakan masyarakat dapat mempengaruhi seseorang secara signifikan, apalagi jika hal ini dipertegas dengan ejekan. Budaya kecantikan yang terus dipromosikan oleh media membuat masyarakat menjadi lebih kritis terhadap penampilan giginya. ${ }^{12}$

Seseorang dengan struktur wajah tidak menarik disebabkan oleh maloklusi dapat meningkatkan keinginan untuk mendapatkan perawatan ortodonti. Pernyataan ini didasari oleh kebiasaan yang berlaku dimasyarakat di mana walaupun karakter dan perilaku seseorang menentukan kualitas dirinya, tetapi faktor situasi sosial lebih dominan menentukan perilaku dibandingkan kepribadian. Seseorang akan lebih bahagia apabila ia merasa dirinya diterima dan dihargai dalam interaksi sosialnya. Apabila penerimaan sosial tidak tercapai, seseorang dapat menjadi kurang percaya diri. ${ }^{13}$

Menurut Motloba et al., (2016) perempuan lebih berminat terhadap perawatan ortodonti dibandingkan laki-laki. Hal ini dikarenakan perempuan cenderung merasa tidak puas dengan penampilan giginya dan menempatkan kecantikan sebagai prioritas utama dibandingkan laki-laki. Individu mengutamakan masalah estetika gigi dan diikuti oleh permasalahan fungsional dari maloklusi. Selain itu, usia remaja akhir juga menunjukkan minat yang lebih besar dalam perawatan ortodonti dibandingkan usia dewasa muda. Hal ini dikaitkan dengan keinginan untuk mengikuti tren dari waktu ke waktu yang didukung oleh kemajuan teknologi dan informasi untuk mencari intervensi yang dapat meningkatkan status mereka seperti pemakaian ortodonti. ${ }^{14}$

Pemakaian peranti ortodonti cekat selain untuk memaksimalkan estetika gigi juga dapat meningkatkan status psikososial seseorang. ${ }^{15} \mathrm{Hal}$ ini dikarenakan tampilan gigi dapat mempengaruhi asumsi seseorang mengenai latar belakang keluarga, pendidikan dan kelas sosial. Perawatan ortodonti juga memberikan pengaruh positif secara subjektif bagi perempuan dan laki-laki,usia muda maupun usia tua. ${ }^{13}$ 
Pengaruh pemakaian peranti ortodonti cekat terhadap status psikososial

\section{KESIMPULAN}

Penelitian ini menyimpulkan bahwa terdapat pengaruh pemakaian peranti ortodonti cekat dengan status psikososial mahasiswa Fakultas Kedokteran Gigi Universitas Prima Indonesia.

\section{REFERENSI}

1. Lestari N, Puspitasari Y, Masdar.Tri Audia. Hubungan Lama Penggunaan Alat Ortodontik Cekat Terhadap Akumulasi Plak dan pH Saliva Mahasiswa FKG-UMI Tahun 2017. As-Syifaa J Farm. 2018;10(01):126-133.

2. Adha MAR, Wibowo D, Rasyid NI. Gambaran tingkat keparahan maloklusi menggunakan handicapping malocclusion assessment record (HMAR) pada siswa SDN Gambut 10. Dentin J Kedokt Gigi. 2019;3(1):1-9.

3. Aftitah V. Hubungan Maloklusi terhadap Kualitas Hidup Remaja dan Dewasa Muda di RSGM Fakultas Kedokteran Gigi Universitas Hasanuddin. 2015.

4. Utari TR, Putri MK. Orthodontic Treatment Needs in Adolescents Aged 13-15 Years Using Orthodontic Treatment Needs Indicators. J Indones Dent Assoc. 2019;2(2):49. doi:10.32793/jida.v2i2.402

5. Indriyanti R, Efendi SH, Maskoen AM, Riyanti E. Predisposing factors analysis of mandibular anterior tooth crowding in the mixed dentition period by the tooth size and dental arch width. Padjadjaran J Dent. 2018;30(3):208. doi:10.24198/pjd.vol30no3.18375

6. Sakinah N, Wibowo D, Helmi ZN. Peningkatan Lebar Lengkung Gigi Rahang Atas Melalui Perawatan Ortodonti Menggunakan Sekrup Ekspansi. Dentino J Kedokt Gigi. 2016;1(1):83-87.

7. Suci RA, Saputri D, Sungkar S. Gambaran Tingkat Pengetahuan Mengenai Kebersihan Mulut pada Siswa Sekolah Menengah Atas yang Menggunakan Perangkat Ortodonti ( Survei di SMAN 3 Banda Aceh). J Caninus Denstistry. 2016;1(4):20-25.

8. Muzakki ER, Wibowo D, Rasyid NI. Correlation Between Orthodontic Treatment Needs and Psychosocial Condition of Adolescents in SMPN 1 Marabahan. Dentino J Kedokt Gigi. 2020;5(1):39. doi:10.20527/dentino.v5i1.8119

9. Chaplin J. Kamus Lengkap Psikologi. Jakarta: Rajagrafindo Persada; 2011.

10. Taibah S, Al-Hummayani F. Effect of malocclusion on the self-esteem of adolescents. J Orthod Sci. 2017;6(4):123-128. doi:10.4103/jos.JOS_16_17

11. Jolanda J, Maria C, Himawati M. Hubungan antara Persepsi Remaja tentang Penggunaan Alat Ortodontik Cekat dan Minat terhadap Perawatan Maloklusi (Penelitian pada Pelajar SMAK "X" Bandung). Insisiva Dent J Maj Kedokt Gigi Insisiva. 2018;7(1):1-8. doi:10.18196/di.7189

12. Twigge E, Roberts RM, Jamieson L, Dreyer CW, Sampson WJ. The psycho-social impact of malocclusions and treatment expectations of adolescent orthodontic patients. Eur J Orthod. 2016;38(6):593-601. doi:10.1093/ejo/cjv093

13. Butar-Butar RF. Hubungan Tingkat Kebutuhan Perawatan Ortodonsia dengan Status Psikososial Pasien pada Klinik RSGM-P Fakultas Kedokteran Gigi Universitas Sumatera Utara. 2017.

14. Motloba DP, Sethusa MPS, Ayo-Yusuf OA. The psychological impact of malocclusion on patients seeking orthodontic treatment at a South African oral health training centre . South African Dent J . 2016;71:200-205.

15. Utami S. Hubungan Perawatan Ortodontik Dengan Status Psikososial Pada Mahasiswa Fakultas Kedokteran Gigi Universitas Hasanuddin. 2014. 